\title{
Efisiensi Penggunaan Faktor Produksi pada Usahatani Padi Sawah di Subak Sembung Desa Peguyangan Kecamatan Denpasar Utara (Penerapan Analisis Stokastik Frontier)
}

\author{
NI MADE RIANA FITRI, DWI PUTRA DARMAWAN, I KETUT SUAMBA \\ Program Studi Agribisnis, Fakultas Pertanian, Universitas Udayana \\ Jl. PB. Sudirman Denpasar 80323 \\ Email : rianafitri11@gmail.com \\ dwiputradarmawan@yahoo.com
}

\begin{abstract}
Efficient Use of Production Factors on Wetland Rice Farming in Subak Sembung, Peguyangan Village, District of North Denpasar (Application of Frontier Stochastic Analysis)
\end{abstract}

Subak Sembung is one of the subaks which get subsidy in the form of seed and fertilizer from the government. The existence of these subsidies allows wastefulness by farmers in the use of production factors. Based on this, a research was conducted that aimed to determine the efficiency of the use of production factors on rice farming in Subak Sembung. Random sampling technique was used to select the sample. The data collection in this study was conducted from October to November 2016. Researchers used the frontier production function and frontier cost functions estimated using the Maximum Likelihood Estimate (MLE) method. The results showed that rice farmers in Subak Sembung were efficient in using the production factor (cut-off value $\geq 0.7$ ), but not in optimum efficiency condition at the frontier limit. Although farmers did not use production factors optimally, they had the opportunity to achieve optimal productive efficiency. Based on the result of significance with Fastilizer Stochastic analysis, it is known that only variable of land area that have a significant effect on paddy rice production.

Keywords: efficiency, production factor, rice

\section{Pendahuluan}

\subsection{Latar belakang}

Pembangunan di sektor pertanian dijadikan prioritas utama dalam meningkatkan perekonomian, serta mencapai ketahanan pangan. Menurut Soekartawi (2005) selain untuk memenuhi kebutuhan pangan, pembangunan pertanian diarahkan untuk meningkatkan produksi pertanian, memenuhi kebutuhan industri dalam negeri, meningkatkan ekspor, meningkatkan pendapatan petani, memperluas kesempatan kerja, dan mendorong pemerataan kesempatan berusaha. 
Salah satu subsektor yang termasuk ke dalam sektor pertanian adalah subsektor tanaman pangan. Subsektor ini sangat penting karena setiap masyarakat memerlukan makanan untuk bertahan hidup. Beras merupakan pangan pokok yang sangat dominan, sehingga usahatani padi masih menjadi andalan petani untuk memenuhi kebutuhan rumah tangganya maupun kebutuhan masyarakat. Menurut Suparyono dan Setyono (1993, dalam Yudanti, 2008) padi (Oryza sativa) adalah tanaman pertanian yang sampai sekarang menjadi tanaman utama dunia.

Berdasarkan BPS Provinsi Bali (2016) produksi padi pada tahun 2015 sebesar 853.710 ton GKG. Produksi padi mengalami penurunan sebesar 4.234 ton GKG $(0,49 \%)$ dibandingkan tahun 2014. Penurunan ini dipengaruhi oleh berbagai faktor dalam menjalankan usahatani, salah satunya adalah luas lahan yang dimanfaatkan untuk bertani padi. Semakin rendahnya luas panen padi menyebabkan produksi padi mengalami penurunan. Tindakan alih fungsi lahan pertanian terutama di daerah perkotaan dalam hal ini sering dikaitkan dengan penurunan luas panen, sehingga luas panen dan produksi padi di perkotaan khususnya di Kota Denpasar adalah yang paling rendah. Berikut merupakan data luas panen, produktivitas, dan produksi padi di Provinsi Bali.

Tabel 1.

Luas Panen, Produktivitas, dan Produksi Padi di Provinsi Bali

\begin{tabular}{lccc}
\hline Kabupaten/Kota & Luas Panen (ha) & Produktivitas (kw/ha) & Produksi (ton) \\
\hline Tabanan & 32.374 & 72,18 & 233.681 \\
Gianyar & 31.009 & 59,53 & 184.592 \\
Buleleng & 21.135 & 64,30 & 135.905 \\
Badung & 16.807 & 67,06 & 112.705 \\
Karangasem & 11.082 & 67,39 & 74.687 \\
Jembrana & 9.784 & 57,74 & 56.494 \\
Klungkung & 5.761 & 51,03 & 29.401 \\
Bangli & 4.934 & 55,36 & 27.317 \\
Denpasar & 4.499 & 58,24 & 26.200 \\
\hline
\end{tabular}

Sumber : BPS Provinsi Bali (2015)

Menghindari degradasi lahan pertanian terutama di daerah perkotaan, tentu perlu upaya lebih agar lahan tersebut tidak beralih fungsi menjadi bangunan, seperti misalnya bangunan pendukung pariwisata yang terkadang menimbulkan kerugian bagi para petani disekitarnya. Menjaga kelestarian lingkungan pertanian penting dilakukan, sehingga pertanian yang berbasis ekowisata sangat tepat untuk dijalankan di daerah tersebut.

Salah satu subak di daerah perkotaan yang berbasis ekowisata adalah Subak Sembung yang terletak di Desa Peguyangan, Kecamatan Denpasar Utara. Subak Sembung adalah subak yang berada di kawasan hijau Kota Denpasar, sehingga subak 
ini menjaga kelestarian lingkungan dengan membuat aturan bahwa bila ada yang menjual tanah sawah, harus tetap fungsinya sebagai sawah. Hal itu tentunya menguntungkan petani di subak tersebut, karena dengan terjaganya kelestarian subak dapat memperlancar kegiatan usahatani yang dijalankan oleh petani di Subak Sembung, sehingga petani bisa lebih fokus untuk bertani dan mampu meningkatkan produktivitas usahatani khususnya padi sawah.

Harga produksi padi yang tinggi bisa saja terjadi, karena mudahnya akses jalan yang ada di kawasan Ekowisata Subak Sembung, sehingga petani tidak mengalami banyak hambatan dalam menjual hasil usahatani mereka, terutama kepada pedagang pengumpul. Permasalahan petani mengenai penggunaan faktor produksi di daerah perkotaan adalah tenaga kerja untuk kegiatan bertani yang terkadang sulit untuk dicari. Selain itu, petani padi sawah di Subak Sembung telah memperoleh subsidi berupa benih dan pupuk dari pemerintah. Adanya subsidi biasanya dapat mengurangi biaya produksi yang dikeluarkan oleh petani, namun dari subsidi tersebut terdapat peluang bahwa adanya pemborosan petani dalam menggunakan faktor produksi.

Petani sebagai pelaku utama dalam berusahatani tentu ingin berproduksi secara optimal dan menguntungkan. Hasil yang optimal dan menguntungkan dapat diperoleh apabila petani padi sawah menggunakan faktor produksi secara efisien. Berdasarkan pemaparan di atas, maka studi mengenai efisiensi penggunaan faktor produksi perlu untuk dilaksanakan di Subak Sembung, Desa Peguyangan, Kecamatan Denpasar Utara.

\subsection{Rumusan Masalah}

Berdasarkan latar belakang di atas, adapun perumusan masalah yang diambil, yaitu bagaimana efisiensi teknis, efisiensi harga (alokatif), dan efisiensi ekonomis pada usahatani padi sawah di Subak Sembung, Desa Peguyangan, Kecamatan Denpasar Utara.

\subsection{Tujuan Penelitian}

Berdasarkan perumusan masalah yang dikemukakan, maka tujuan dari penelitian ini adalah untuk mengetahui tingkat efisiensi teknis, efisiensi harga (alokatif), dan efisiensi ekonomis pada usahatani padi sawah di Subak Sembung, Desa Peguyangan, Kecamatan Denpasar Utara.

\section{Metode Penelitian}

\subsection{Lokasi dan Waktu Penelitian}

Penelitian dilakukan di Subak Sembung, Desa Peguyangan, Kecamatan Denpasar Utara dan dilaksanakan pada bulan Oktober sampai November 2016. Pemilihan lokasi dilakukan dengan metode purposive (sengaja) yang berdasarkan atas pertimbangan bahwa Subak Sembung merupakan subak yang pernah memperoleh juara pertama dalam lomba subak dan juara kedua dalam evaluasi 
penerapan teknologi padi di tingkat provinsi pada tahun 2014 dan merupakan subak yang berada di daerah perkotaan dan berbasis ekowisata.

\subsection{Metode Pengumpulan Data dan Variabel Penelitian}

Data mengenai usahatani padi sawah di Subak Sembung dikumpulkan melalui wawancara dengan berpedoman pada kuisioner yang dipersiapkan sebelumnya. Variabel - variabel yang dianalisis adalah : (1) jumlah produksi; (2) jumlah faktor produksi; (3) harga produksi; (4) harga masing - masing faktor produksi. Variabel tersebut dianalisis dengan metode deskriptif kuantitatif untuk menganalisis efisiensi penggunaan faktor produksi dan dijelaskan dengan deskriptif kualitatif.

\subsection{Penentuan Sampel dan Teknik Pengambilan Sampel}

Menurut Soekartawi (2006), sampel merupakan bagian dari anggota populasi yang dalam hal ini terpilih sebagai objek pengamatan. Metode yang digunakan dalam penentuan sampel adalah dengan rumus Slovin, yaitu (Setiawan, 2007) :

$$
\mathrm{n}=\frac{\mathrm{N}}{1+\mathrm{Ne}^{2}}
$$

Keterangan :

$\mathrm{n} \quad=$ jumlah sampel

$\mathrm{N} \quad=$ jumlah populasi

e = batas toleransi kesalahan (error tolerance)

Penelitian ini menggunakan teori Slovin dengan batas toleransi kesalahan sebesar $10 \%$, sehingga jumlah sampel yang diperoleh berdasarkan hasil perhitungan sebanyak 66 petani dari 192 petani di Subak Sembung. Pemilihan sampel dilakukan dengan undian, dimana setiap petani memiliki kesempatan yang sama untuk dipilih menjadi sampel.

\subsection{Metode Analisis}

Analisis efisiensi penggunaan faktor produksi menggunakan fungsi produksi stokastik frontier (stochastic frontier). Spesifikasi fungsi produksi stokastik frontier adalah sebagai berikut.

$\operatorname{LnY}=\beta_{0}+\beta_{1} \operatorname{Ln} X_{1}+\beta_{2} \operatorname{Ln} X_{2}+\beta_{3} \operatorname{Ln} X_{3}+\beta_{4} \operatorname{Ln} X_{4}+\beta_{5} \operatorname{Ln} X_{5}+\beta_{6} \operatorname{Ln} X_{6}+\beta_{7} \operatorname{LnX} X_{7}+V_{i}-u_{i}$

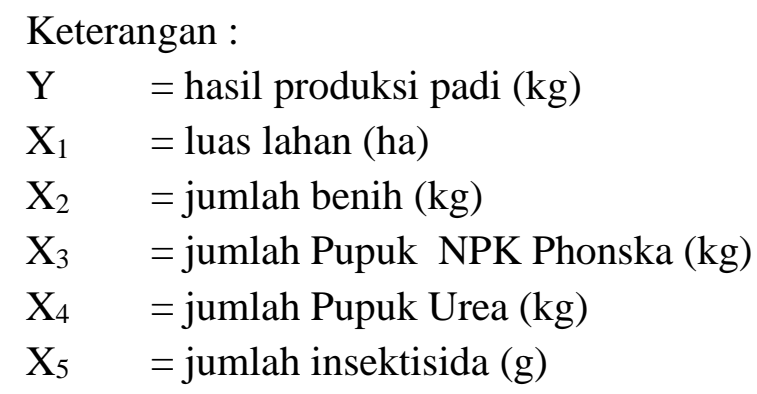


$\mathrm{X}_{6} \quad=$ jumlah herbisida $(\mathrm{g})$

$\mathrm{X}_{7} \quad=$ jumlah tenaga kerja $(\mathrm{HOK})$

$\mathrm{v}_{\mathrm{i}}-\mathrm{u}_{\mathrm{i}}=$ error term $\left(\mathrm{u}_{\mathrm{i}}\right)$ efek efisiensi teknis dalam model, error term $\left(\mathrm{v}_{\mathrm{i}}\right)=$ noise.

Nilai dugaan efisiensi teknis (technical efficiency estimates) dapat diukur dengan analisis fungsi produksi stochastic frontier dengan menggunakan formula sebagai berikut.

$$
\mathrm{TEi}=\frac{\mathrm{E}\left(\mathrm{YU}_{\mathrm{i}}, \mathrm{X}_{\mathrm{i}}\right)}{\mathrm{E}\left(\mathrm{Y}^{*} \mathrm{Ui}_{\mathrm{i}}=0, \mathrm{Xi}\right)}=\mathrm{E}[\exp (-\mathrm{Ui}) \| \varepsilon \mathrm{i}]
$$

Keterangan :

$\mathrm{TE}_{\mathrm{i}} \quad=$ efisiensi teknis petani ke-i

$\left[\exp \left(-\mathrm{U}_{\mathrm{i}}\right) \mid \varepsilon_{\mathrm{i}}\right]=$ nilai harapan (mean) dari $\mathrm{u}_{\mathrm{i}}$ dengan syarat $\varepsilon_{\mathrm{i}}$ dan nilai TE berkisar antara $0 \leq \mathrm{TE} \leq 1$. Secara teknis produsen disebut efisien jika memiliki rating efisiensi teknis $\geq 0,70$ (cut-off value). Pengukuran efisiensi alokatif dan efisiensi ekonomis dapat dilakukan dengan menurunkan fungsi biaya dual dari fungsi produksi Cobb-Douglas yang homogeneus (Debertin, 1986 dalam Darmawan, 2016). Fungsi biaya dual frontier dapat diperoleh dengan cara meminimumkan fungsi biaya input dengan kendala fungsi produksi stokastik frontier sebagai berikut.

$$
C=f\left(Y, P_{1}, P_{2}, P_{3}\right)
$$

$\mathrm{C}$ merupakan biaya produksi (Rp), $\mathrm{Y}$ adalah hasil produksi padi $(\mathrm{kg})$, dan $\mathrm{P}_{1}-\mathrm{P}_{3}$ (semuanya dalam Rp) berturut - turut adalah harga benih, harga pupuk, dan harga pestisida. Efisiensi ekonomis (EE) adalah rasio antara total biaya produksi yang diobservasi $\left(\mathrm{C}^{*}\right)$ dengan total biaya produksi aktual $(\mathrm{C})$. Sehingga dapat dirumuskan sebagai berikut.

$$
\mathrm{EE}=\frac{\mathrm{C}^{*}}{\mathrm{C}}=\frac{\mathrm{E}\left(\mathrm{C}_{\mathrm{i}} \mid \mathrm{u}_{\mathrm{i}}=\mathrm{O}_{,}, \mathrm{Y}_{\mathrm{i}}, \mathrm{P}_{\mathrm{i}}\right)}{\mathrm{E}\left(\mathrm{C}_{\mathrm{i}} \mid \mathrm{u}_{\mathrm{i}}, \mathrm{Y}_{\mathrm{i}}, \mathrm{P}_{\mathrm{i}}\right)}=\mathrm{E}\left[\exp \frac{\mathrm{U}_{\mathrm{i}}}{\varepsilon}\right]
$$

EE bernilai $0<\mathrm{EE}<1$. Efisiensi ekonomis (EE) adalah gabungan dari efisiensi teknis (TE) dan efisiensi alokatif (AE), maka AE diperoleh dengan formula berikut.

$$
\mathrm{AE}=\frac{\mathrm{EE}}{\mathrm{TE}}
$$

Sama halnya dengan efisiensi teknis, petani dapat dikatakan efisien dari segi harga apabila nilai efisiensi harga $\geq 0,70$. 


\section{Hasil dan Pembahasan}

\subsection{Efisiensi Teknis pada Usahatani Padi Sawah di Subak Sembung Peguyangan}

Tabel 2.

Hasil Estimasi Fungsi Produksi Stokastik Frontier dengan TE Effects Model

\begin{tabular}{cccccc}
\hline Parameter & Variable & Coefficient & $\begin{array}{c}\text { Standard- } \\
\text { error }\end{array}$ & t-ratio & Sign. \\
\hline beta 0 & Constant & 4,1765 & 0,9232 & 4,5238 & $* *$ \\
beta 1 & Luas lahan & 1,1577 & 0,5173 & 2,2380 & $*$ \\
beta 2 & Benih & $-0,0251$ & 0,4973 & $-0,0506$ & ns \\
beta 3 & Pupuk NPK Phonska & $-0,0572$ & 0,7991 & $-0,0715$ & Ns \\
beta 4 & Pupuk Urea & $-0,1118$ & 0,6831 & $-0,1637$ & Ns \\
beta 5 & Insektisida & 0,0013 & 0,4667 & 0,0028 & Ns \\
beta 6 & Herbisida & $-0,0290$ & 0,6732 & $-0,0430$ & Ns \\
beta 7 & Tenaga kerja & 0,0941 & 0,8867 & 0,1062 & Ns \\
delta 1 & Umur & $-0,0349$ & 0,4393 & $-0,0794$ & Ns \\
delta 2 & Pendidikan & 0,0034 & 0,8498 & 0,0040 & Ns \\
delta 3 & Pengalaman & 0,0484 & 0,5526 & 0,0876 & Ns \\
\hline
\end{tabular}

Keterangan :

a. $* *=$ signifikan $\alpha=1 \%(2,6633)$

b. $*=$ signifikan $\alpha=5 \%(2,0017)$

c. $\mathrm{ns}=$ tidak signifikan

Sumber : Data primer diolah (2017)

Menurut Dewi (2015) tanah/lahan merupakan faktor produksi yang sangat dominan dalam produksi usahatani dibandingkan dengan faktor iklim dan pengairan. Berdasarkan tabel 2, diketahui bahwa hanya variabel luas lahan yang berpengaruh secara signifikan $(\alpha=5 \%)$ dengan elastisitas positif terhadap produksi padi sawah, sedangkan variabel lainnya tidak berpengaruh signifikan tetapi insektisida dan tenaga kerja memiliki elastisitas positif. Ketiga faktor penyebab inefisiensi yang terdiri dari umur, pendidikan, dan pengalaman memberikan hasil yang tidak sesuai harapan terutama pada faktor pendidikan dan pengalaman petani. Semakin tinggi pendidikan dan semakin berpengalaman petani, seharusnya dapat menurunkan tingkat inefisiensi. Analisis ini menggunakan tujuh variabel, namun enam diantaranya tidak signifikan, maka dari itu peranan dari penyuluh pertanian dalam hal ini diperlukan untuk memberikan informasi kepada petani dalam penggunaan input yang tepat.

Menurut Soekartawi (2001) efisiensi teknis adalah hubungan antara tingkat penggunaan input dan output yang dihasilkan. Adapun rata-rata efisiensi teknis petani padi sawah di Subak Sembung yang diperoleh dengan analisis Stokastik Frontier adalah 0,9450. Secara teknis, petani tergolong efisien dalam menggunakan faktor produksi dengan cut-off value $\geq 0,7$, namun belum efisien secara optimal pada posisi frontier. Fungsi produksi yang dapat dibuat berdasarkan tabel 1, yaitu : 


$$
\begin{aligned}
\operatorname{Ln} Y & =4,1765+1,1577 \operatorname{Ln} X_{1}-0,0251 \operatorname{Ln} X_{2}-0,0572 \operatorname{Ln} X_{3}-0,1118 \operatorname{Ln} X_{4} \\
& +0,0013 \operatorname{Ln} X_{5}-0,0290 \operatorname{Ln} X_{6}+0,0941 \operatorname{LnX}_{7}
\end{aligned}
$$

\subsection{Efisiensi Harga dan Ekonomis pada Usahatani Padi Sawah Subak Sembung}

Tabel 3.

Hasil Estimasi Fungsi Biaya Produksi Stokastik Frontier

\begin{tabular}{cccccc}
\hline Parameter & Variable & Coefficient & $\begin{array}{c}\text { Standard- } \\
\text { error }\end{array}$ & t-ratio & Sign. \\
\hline beta 0 & Constant & $-1,4425$ & 0,9648 & $-1,4952$ & Ns \\
beta 1 & P Benih & 0,0048 & 0,7819 & 0,0061 & Ns \\
beta 2 & P Pupuk NPK Phonska & 0,1949 & 0,3837 & 0,5081 & Ns \\
beta 3 & P Pupuk Urea & 0,1677 & 0,3946 & 0,4250 & Ns \\
beta 4 & P Insektisida & 0,0013 & 0,0606 & 0,0218 & Ns \\
beta 5 & P Herbisida & $-0,4181$ & 0,7258 & $-0,5761$ & Ns \\
beta 6 & P Tenaga kerja & 1,4248 & 0,7400 & 1,9253 & Ns \\
delta 1 & Umur & $-0,0285$ & 0,2089 & $-0,1363$ & Ns \\
delta 2 & Pendidikan & 0,0051 & 0,2388 & 0,0216 & Ns \\
delta 3 & Pengalaman & 0,0418 & 0,2019 & 0,2067 & Ns \\
sigma-squared & & 0,0023 & 0,0007 & 3,4396 & $* *$ \\
Gamma & & 0,0077 & 0,3732 & 0,0207 & Ns \\
\hline Keterangan
\end{tabular}

Keterangan :
a. $* *=$ signifikan $\alpha=1 \%(2,6633)$
b. $*=$ signifikan $\alpha=5 \%(2,0017)$
c. $\mathrm{ns}=$ tidak signifikan

Sumber : Data primer diolah (2017)

Hasil estimasi fungsi biaya menginformasikan bahwa tidak ada variabel yang berpengaruh signifikan terhadap harga produksi padi sawah. Faktor penyebab ketidakoptimalan yang menyebabkan inefisiensi juga tidak menghasilkan sesuai dengan yang diharapkan.

Rating efisiensi biaya (cost efficiency) yang diperoleh dengan analisis fungsi biaya Stokastik Frontier antara 1,0006 - 1,1016 dengan nilai rata - rata sebesar 1,0117. Efisiensi ekonomis (economic efficiency) merupakan invers dari efisiensi biaya, dan efisiensi harga (allocative efficiency) adalah rasio dari efisiensi ekonomis dan efisiensi teknis (Ali dan Byerlee, 1991 ; Parikh et al., 1995 ; Alpizar, 2007 dalam Darmawan, 2016). Statistik deskriptif tingkat efisiensi teknis, harga (alokatif), dan ekonomis disajikan pada tabel 4. 
Tabel 4.

Statistik Deskriptif Tingkat Efisiensi (TE, AE, dan EE)

\begin{tabular}{ccccc}
\hline Indeks efisiensi & $\mathrm{N}$ & Minimum & Maximum & Mean \\
\hline $\mathrm{TE}$ & 66 & 0,8113 & 0,9997 & 0,9450 \\
$\mathrm{AE}$ & 66 & 0,9920 & 1,2232 & 1,0489 \\
$\mathrm{EE}$ & 66 & 0,9078 & 0,9994 & 0,9887 \\
\hline Valid N (listwise) & 66 & & & \\
\hline \multicolumn{5}{l}{ Sumber : Data primer diolah (2017) }
\end{tabular}

Nilai efisiensi alokatif paling tinggi yang dicapai oleh petani padi sawah di Subak Sembung adalah 1,2232 dengan rata - rata 1,0489. Petani dapat dikatakan efisien apabila memiliki rating $\geq 0,7$. Nilai rata - rata efisiensi alokatif tersebut menunjukkan bahwa petani padi sawah di Subak Sembung tergolong efisien menggunakan faktor produksi. Peluang petani untuk mencapai efisiensi harga tertinggi adalah $14,25 \%$.

\section{Simpulan dan Saran}

\subsection{Simpulan}

Berdasarkan hasil penelitian, pengukuran efisiensi menggunakan Stochastic Frontier Analysis (SFA) dengan metode Maximum Likelihood Estimation (MLE) menunjukkan bahwa petani padi sawah di Subak Sembung tergolong efisien dalam menggunakan faktor produksi dengan cut-off value $\geq 0,7$ secara individual maupun secara rata - rata, namun belum mencapai efisiensi optimal (pada posisi frontier).

\subsection{Saran}

Adapun saran yang dapat penulis sampaikan, yakni sebaiknya petani padi sawah di Subak Sembung memanfaatkan subsidi yang diberikan oleh pemerintah dengan sebaik - baiknya, agar tidak terjadi pemborosan dalam menggunakan faktor produksi tersebut. Bagi peneliti lain yang ingin mengembangkan penelitian ini, diharapkan kedepannya mampu menganalisis efisiensi penggunaan faktor produksi secara parsial agar mampu membuat keputusan dalam menambah atau mengurangi penggunaan faktor produksi.

\section{Ucapan Terimakasih}

Ucapan terimakasih penulis tujukan kepada semua pihak yang telah membantu penulis dalam melaksanakan penelitian hingga karya ilmiah ini bisa dipublikasikan dalam e-jurnal.

\section{Daftar Pustaka}

BPS Provinsi Bali. 2015. Luas Panen dan Produksi Kabupaten/Kota di Bali. http://bali.bps.go.id/tabel_detail.php?ed=607002\&od=7\&id7. Diakses pada tanggal 7 Juli 2016 
BPS Provinsi Bali. 2016. Berita Resmi Statistik Produksi Padi Tahun 2014 (Angka Sementara). https://www.bps.go.id/Brs/view/id/1122.pdf. Diakses pada tanggal 7 Juli 2016

Darmawan, Dwi Putra. 2016. Pengukuran Efisiensi Produktif Menggunakan Pendekatan Stochastic Frontier. New Elmatera Publisher. Yogyakarta

Dewi, Ratna Komala. 2015. Bahan Ajar Manajemen Usahatani. Fakultas Pertanian Universitas Udayana. Denpasar

Setiawan, dan Bowo. 2015. Efisiensi Teknis, Alokatif, dan Ekonomi Budidaya Padi. Journal of Economics and Policy. http://dx.doi.org. Diakses pada tanggal 30 Oktober 2016

Setiawan, Nugraha. 2007. Penentuan Ukuran Sampel Memakai Rumus Slovin dan Tabel Krejcie-Morgan: Telaah Konsep dan Aplikasinya. http://pustaka.unpad.ac.id/wp-

content/uploads/2009/03/penentuan_ukuran_sampel_memakai_rumus_slovi n.pdf. Diakses pada tanggal 7 Juli 2016

Soekartawi. 2001. Agribisnis Teori dan Aplikasinya. Edisi 1. PT Raja Grafindo Persada. Jakarta

Soekartawi. 2005. Prinsip Dasar Ekonomi Pertanian. PT Raja Grafindo Persada. Jakarta

Soekartawi. 2006. Analisis Usahatani. UI-Press. Jakarta

Yudanti, Sri. 2008. Efisiensi Penggunaan Faktor Produksi pada Usahatani Padi di Subak Babadan, Desa Mengwitani, Kecamatan Mengwi, Kabupaten Badung. Skripsi Sosial Ekonomi Pertanian. Universitas Udayana. Denpasar 